\title{
Body of ice: The movement of Antarctic ice through dance
}

\author{
Christina Evans ${ }^{1}$
}

\begin{abstract}
Antarctic ice is fragile, dynamic and alive. The journey of an ice form is continually transient. Layering, compressing, flowing, cracking, floating, crumbling, dissolving, freezing and reforming occurs at a molecular level and large scale. The diverse textures, qualities and forms of Antarctic ice are extraordinary. Seasonal cycles of ice see Antarctica double in size as it expands through fierce winter and contracts through summer. Snow forms in layers on the plateau and compresses, forming ice. Glaciers flow to the coast to form ice shelves that break as icebergs. Such cycles take thousands of years, yet are always in motion. Our bodies are made up of pure water that at some point has been Antarctic ice. We are a part of the ice as well as its signs of a changing climate. ${ }^{2}$
\end{abstract}

Body of Ice is a contemporary dance work that explores the dynamic movement and extreme nature of Antarctic ice, as well as the human connection to and impact on it. As the first dance artist ever to be awarded an Australian Antarctic Arts Fellowship, I travelled to Antarctica for several weeks in 2010 to undertake creative research to develop this work. Many facets of Antarctic ice movement were researched, explored and integrated into choreographic processes. Collaborating with renowned sound artist Philip Samartzis, a fellow Australian Antarctic Arts Fellowship recipient, the Body of Ice soundscape was born from the raw, richly diverse and intricate sounds of Antarctic ice. Several art forms were utilised to create a sensory representation of the ice and one which physically connect us to it.

\section{Creative research in Antarctica}

The shapes and layers of an ice structure reveal its movement history; the many processes of action and reaction that created its current yet continually changing form. While in Antarctica I collected a vast range of movement and choreographic stimuli, ice imagery, visual and written responses and sensory

1 Ms Christina Evans, 10 Birks Street, Parkside, SA 5063, christina.evans@outlook.com.

2 From program notes for the author's contemporary dance piece Polarity. 
impressions. The illuminated colour, textures, diversity, scale and raw beauty of the ice were phenomenal, and my physical state was altered through interacting with it. My diary entry stated:

I am full of awe, wonder and passion. The ice lives and breathes. Beautiful, severe, natural. Delicate fluidity, rock hard strength. Staggering. ${ }^{3}$

I undertook research into ice types, ice cycles and ice behaviours as well as into the signs of a changing climate that are evident in the Antarctic. Although this research was somewhat basic as I do not have a scientific background, I wanted to ensure that the complexities of the ice and environmental shifts were accurately referenced within the layers of my work.

\section{Choreographic processes}

Various processes were used in translating the movement of Antarctic ice into choreographic material, including image, sensory, kinaesthetic, dynamic and structurally based explorations. Image-based responses included dancers looking at photographic images of Antarctic ice and responding to the shape, patterns, lines and layers seen within the ice forms. A physical journey of how the ice form became its current shape generated movement material, as well as moving through space in a way that an ice form tracks through the ocean or among surrounding ice. Textures, rolling, crumbling, melting and freezing were explored through intricate parts of the body and through bodies interacting with each other. Dancers could all be one piece of ice, varying types of ice, or their individual bodies could split into various types of ice with varying qualities of movement, speed and dynamics.

Water and ice itself were explored in several ways. Dancers danced with actual ice and also performed movement material on plastic sheets covered with ice in the studio. I conducted several rehearsals in swimming pools to explore the effect, sensations and qualities of being in water. The fluidity and impact water made on body movement was dramatic, and these qualities were brought into the choreographic material. Raw sounds of Antarctic ice, recorded by Samartzis, were used, with dancers reacting to the sounds of ice physically, and moving as if actually being the ice that was creating the sounds. The water in our physical composition was a pivotal exploration as this would have been Antarctic ice at one point in time, therefore we are literally a part of Antarctic ice and its cycles and processes.

3 Probably written at Davis station, Antarctica, around 7 February 2010. 
Extreme qualities of ice were explored physically, such as strength, fragility, soft and hard ice, as well as the unpredictable nature of the Antarctic environment explored through kinaesthetic response. Dancers would move through a piece of choreography and I would shift the speed, direction or dynamic of the material, stating the switch and effecting sudden dramatic change in an instant. Extremely fast and extremely slow speeds were also explored, including moving at no faster than one centimetre per second for extended periods of time. Ice exploration also extended into the use of structures and fabrics, presenting the interconnected nature of the ice where one form of ice would become another. Each choreographic process had a deep link with Antarctic ice and allowed for extreme facets of choreography to develop in line with the nature of the ice.

\section{Choreographic structure}

The overall choreographic structure of Body of Ice follows the creation cycle and seasonal cycle of Antarctic ice. A journey from the ice plateau expands outwards through glacial flow, ice shelf formation and the breakage of icebergs, along with a range of ice interactions and qualities. A retreat of sea ice during the summer, plus the signs of excessive melting of Antarctic ice, forms the ending - a vivid image of bodies melting away. Throughout the work dancers articulate ice patterns, imagery and dynamics at a cellular level as well as through their connections with each other.

\section{Soundscape}

The soundscape by Samartzis recorded near Australia's Davis station includes sounds of Antarctic ice taken from Antarctic Plateau, Brash Ice at Heidemann Bay, Seal Cove and Law Cairn, Frozen Lake at Ellis Fjord and Trajer Ridge, Icebergs at Anchorage Bay, Sea Ice at Seal Cove and Growler Ice at Long Fjord.

\section{Photographic imagery}

Macro and micro photographic imagery of Antarctic ice, taken by Antarctic expeditioners Fred Olivier, Ruth Wielinga and me, is used as projection in Body of Ice. This visual element contextualises sections of the work with images of intricate and unique aspects of Antarctic ice. 


\section{Interaction of artistic forms}

Body of Ice employs the artistic forms of dance, sound, photographic imagery and lighting. Each layer presents elements of Antarctic ice that integrate into all of the senses. The experience of Antarctic ice is one words cannot communicate, and the beauty of raw movement, real sound, vivid imagery and illumination of light and colour does present felt experiences of the Antarctic environment. The essential performance language of dance brings the Antarctic ice directly to humanity, physically connecting ourselves to Antarctic ice. The voice of the ice is brought to the performance by the extraordinary soundscape, being the true language of Antarctic ice itself. These two languages are further enhanced by photographic imagery and lighting in a stage environment.

\section{Polarity}

After June 2011, Body of Ice was developed into full length work Polarity, presented outdoors as part of the 2011 Melbourne Fringe Festival on the Federation Square carpark roof area. The scale of the area was fitting with Antarctic expanse, and the surrounding city linked the cityscape to the icescapes and presented the connection and impact each has on the other. Audience members were encouraged to walk around the large performance area to view the work from various angles, journeying to experience the ice. The presentation at Federation Square integrated the cityscape which in itself provided a language that communicated our present way of life and how it may be affecting the ice. The sheer scale of the buildings was also symbolic of the scale of icebergs in Antarctica, which seem like 'cities of ice'.

\section{Artistic innovation}

As the first dance artist ever sent by the Australian Antarctic Division to Antarctica, my proposal to create Body of Ice was seen as a unique, ambitious and innovative way to communicate Antarctica through the arts. Body of Ice translates the Antarctic ice environment through performance, highlighting scientific information about its cycles and nature, as well as its physical and emotive connection to us. Body of Ice is a potent reminder at this time that we are intrinsically connected to our environment and that we are a part of the cycles of Antarctic ice. The magnificent beauty and complex nature of Antarctic ice is something that is rarely experienced or acknowledged, and to see it explored through these mediums is an ambitious, yet natural, connection. The Australian 
Antarctic Division seeks for Antarctica to be valued, protected and understood, and to bring Antarctic ice to the public in this way physically connects us to the ice and brings it to life.

\section{Future evolutions}

I envisage touring Body of Ice and Polarity throughout Australia as well as performing in the desert, as Antarctica is a desert. I also plan to connect my work to international audiences, presenting an experience of Antarctic ice to most who would never have the opportunity actually to experience it.

The performance of Polarity at Federation Square in 2011 received wide press coverage and positive responses. I was invited to the IV Antarctica Art and Culture International Conference and Festival in Buenos Aires in 2012, performing a solo version of Body of Ice and presenting a talk on my work and artistic vision. A film of Polarity was presented at the Ultimo Science Festival in Sydney 2013 as part of the Living Data exhibition. I am now working on an installation to perform live and present as a video piece for gallery and festival spaces, focusing on the impact of climate change on Antarctic ice. I plan to expand and evolve my work and continue to present it on a global platform. 
This text is taken from Antarctica: Music, sounds and cultural connections, edited by Bernadette Hince, Rupert Summerson and Arnan Wiesel, published 2015 by ANU Press, The Australian National University, Canberra, Australia. 